\title{
Test-retest standard error of measurements for full-torso surface topography parameters obtained with the arms at 30 and 90 degrees of elevation in healthy teenagers
}

\author{
E Watkins, Eric Parent*, M Emrani, D Hill
}

From 7th International Conference on Conservative Management of Spinal Deformities

Montreal, Canada. 20-22 May 2010

\section{Introduction}

The objective of this study was to report full-torso surface topography (ST) parameters and to determine test-retest standard error of measurement (SEM) in adolescents without spinal deformities. ST is used to quantify the external deformity of the torso due to scoliosis. A normative ST database is being developed to help interpret the ST parameters used to describe scoliosis. Test-retest SEM has not been estimated for most parameters in this population.

\section{Materials and methods}

\section{Subjects}

Forty-two healthy volunteers (43\% females) between 10 18 years old, with a body mass index of $19.7 \pm 3.1 \mathrm{~kg} / \mathrm{m}^{2}$, scoliometer measure of $3.2^{\circ} \pm 1.8^{\circ}$, and without pain were included.

\section{Data acquisition}

Four Minolta 910 Laser Scanners and a positioning frame were used to record ST scans. One evaluator positioned all subjects with arms resting at $90^{\circ}$ of elevation, marked 15 reference points, and scanned. Immediately after, subjects were repositioned and scanning repeated. ST parameters were extracted with custom designed software in Matlab by one evaluator digitizing reference points.

University of Alberta, Edmonton, Canada

Full list of author information is available at the end of the article

\section{ST parameters}

Seven previously published parameters and 7 newly proposed measures were extracted. The total range and the range between the 10th and 90th percentile were reported for the measures extracted from 54 crosssections of the torso.

\section{Statistical analyses}

Test-retest SEM was calculated. SEM $<4 \mathrm{~mm},<5^{\circ}$ or $<0.2$ for a ratio were considered adequate based on values in patients with scoliosis.

\section{Results}

Normative full-torso ST parameter means, standard deviations (SD), and the estimated test-retest SEMs are in Table 1. Fourteen parameters had adequate SEMs. Total range SEMs of the parameters extracted from cross-sections were inadequate for 5 out of the 6 measures. The SEMs for all but one new parameter were adequate.

\section{Discussion}

Test-retest error was adequate for scans with the arms at $90^{\circ}$ of elevation. For parameters obtained from torso cross-sections, the 10-90th percentile range may reduce errors compared to the total range. The percentile range excludes extreme values due to edge, motion or breathing artifacts on the scans while still providing a representation of torso deformity. Scanning with arms in this position provides an unobstructed view of the torso and may reduce error in merging. 


\section{Conclusion}

Adequate test-retest error was found for previously published and newly proposed full-torso ST parameters. For measures of cross-sections, we recommend using the 10-90th percentile range.

Published: 10 September 2010

doi:10.1186/1748-7161-5-S1-O6

Cite this article as: Watkins et al:: Test-retest standard error of

measurements for full-torso surface topography parameters obtained

with the arms at 30 and 90 degrees of elevation in healthy teenagers.

Scoliosis 2010 5(Suppl 1):O6.

Submit your next manuscript to BioMed Central and take full advantage of:

- Convenient online submission

- Thorough peer review

- No space constraints or color figure charges

- Immediate publication on acceptance

- Inclusion in PubMed, CAS, Scopus and Google Scholar

- Research which is freely available for redistribution

Submit your manuscript at www.biomedcentral.com/submit 